\title{
CHEIROS PRAIANOS, LARES COTIDIANOS: PERCORRENDO AS TRILHAS DA COMUNIDADE DE QUATIPURÚ MIRIM ${ }^{1}$
}

Alan Christian Quadros Alvão ${ }^{2}$

Indira Angela Luza Eyzaguirre ${ }^{3}$

Em uma das viagens de explorações e descobertas de outras realidades, nos aproximamos da ilha (praia) de Quatipurú Mirim, onde por casualidade chegamos a conviver uma semana com uma familia praiana que vive da pesca artesanal. Assim este ensaio objetiva reconhecer o conhecimento local, a cultura e a voz da comunidade a partir da aproximação dessa realidade social para compreender as dinâmicas comunitárias.

As ruas de areia, as casas de madeira, as crianças na beira e no horizonte o mar, esse "ente orgânico" e ator principal pelo qual se constroem uma série de imaginários que forman representações socioambientais. Assim, nos aproximamos e chegamos à casa de "Seu Bodinho" e Dona Marilene (esposa), que nos envolveram com todo seu complexo cultural mediante o compartilhar de momentos e de seus conhecimentos, das suas epistemologias materializadas nas práticas cotidianas.

Assim o dia a dia dos comunitários acontece nesse espaço, onde se encontravam materiais de pesca pela casa, como a rede e o óleo para manter o motor do barco do pescador. Aquele dia por exemplo Seu Bodinho estava consertando sua rede, preparando-se para ir pescar como de costume. Ele vai deixando tudo pronto. Sai pela manhã cedo de casa, prepara seu barco de pequeno porte e vai pescar no seu curral ou no seu rancho nas praias próximas.

Acordo cedinho...deixo a maré baixar, pego peixe, logo cuido do peixe. Quando vou pescar é só relaxar, a noite a mesma coisa as vezes vou para o rancho.......a praia aqui, é igual a pesca, eu penso assim. Na arte da pesca, o pescador sempre ele inventa um tipo de armadilha para matar o peixe e mata mais. (Seu bodinho, pescador artesanal, 51 anos)

Depois da pescaria, que durou toda a manhã, ele retorna para casa na hora do almoço trazendo os peixes, caranguejos, siris e arraias que foram pescados, logo dona Marilene trata e cozinha, seja frito, assado ou preparado em um caldo. Naquele dia ela compartilhou conosco seu conhecimento sobre o tratar dos peixes, cada peixe é um tipo diferente de cuidado e também um tipo diferente de técnica no preparo.

Assim as práticas, os costumes dão voz aos comunitários, o que evidencia uma dinâmica social intrínseca ao desenvolvimento do entorno, como nesse caso, que a pesca vem da praia. Todas essas práticas que nós pudemos perceber se baseiam nos recursos que oferece o mar, enquanto elemento principal que suporta toda essa estrutura e de acordo com Diegues (1998, p. 42),

\footnotetext{
${ }^{1}$ Comunidade localizada no Município de Tracuateua.

${ }^{2}$ Estudante do curso de graduação em Ciências Naturais da UFPA, campus Bragança.

${ }^{3}$ Estudante do Programa de Pós Graduação em Biologia Ambiental da UFPA, campus Bragança.
} 
Quando utilizo os conceitos de maritimidade, insularidade e ilheidade para explicar o fenômeno insular, estou partindo da noção de práticas sociais e simbólicas dos ilhéus. Isso quer dizer que o estudo da relação entre as sociedades insulares e seu território se processa por intermédio de práticas econômicas, sociais e simbólicas e não de simples isolamento geográfico ou de endemismos. Na realidade, a vida social na ilha não se define pelo fato de ela estar cercada de água por todos os lados, mas pelas práticas em que estão envolvidos os ilhéus na sua relação com o mar. Nesse sentido, se para algumas sociedades insulares o oceano é considerado obstáculo para os contatos com as sociedades continentais, em outras, ele é uma via de comunicação. Em alguns casos, em diferentes épocas históricas, o oceano pode ser visto ora como obstáculo ora como elemento facilitador dos contatos, dependendo do tipo de práticas econômicas (de mercado ou de subsistência), de práticas sociais, em que estão incluídas as relações de parentesco, as capacidades marinheiras dos ilhéus e das práticas simbólicas(...).

Na despedida nós demos um até logo, mas um bem vindo para o desenvolvimento de projetos futuros. Quatipurú Mirim é uma comunidade que está aberta a realização de pesquisas conscientes que envolvam a comunidade e evitem futuros conflitos com os objetivos das pesquisas ou segundo Nandy (2015, p. 55) menciona no seguinte trecho:

(...) Quando ela (a cultura) se torna uma profissão, e quando um profissional de uma sociedade desenvolvida começa a se interessar pelos recursos artísticos e culturais de uma sociedade "subdesenvolvida", ela naturalmente não continua puramente um desempenho artistico ou uma critica de arte; ela se torna etnomusicologia, etnomuseologia ou especialização em artes étnicas.

Toda essa convivência nos levou a perceber e sentir aquele ar praiano que chega até a nossa face; aquela convivência que inclui histórias contadas de memórias guardadas. A estrada que leva até o porto, o porto que leva àquela ilha, a ilha que leva à praia, o ar na brisa, a areia inundando os nossos pés, a pesca que leva-nos a conhecer pessoas que acolhem com esse calor tão familiar, com açai e buriti nas suas mesas, caldo de turú do mangue e água de coco; tudo isso faz parte desses lares cotidianos que emanam cheiros praianos pelas trilhas da comunidade de Quatipurú Mirim.

\section{REFERÊNCIAS BIBLIOGRÁFICAS}

NANDY, Ashis. A imaginação emancipatória: Desafios do século 21. Tradução por Joannes de Knegt. Editora UFMG. Belo Horizonte. Brasil. 2015.

DIEGUES, Antonio. Ilhas e mares: Simbolismo e imaginário. Brasil. 1998. 


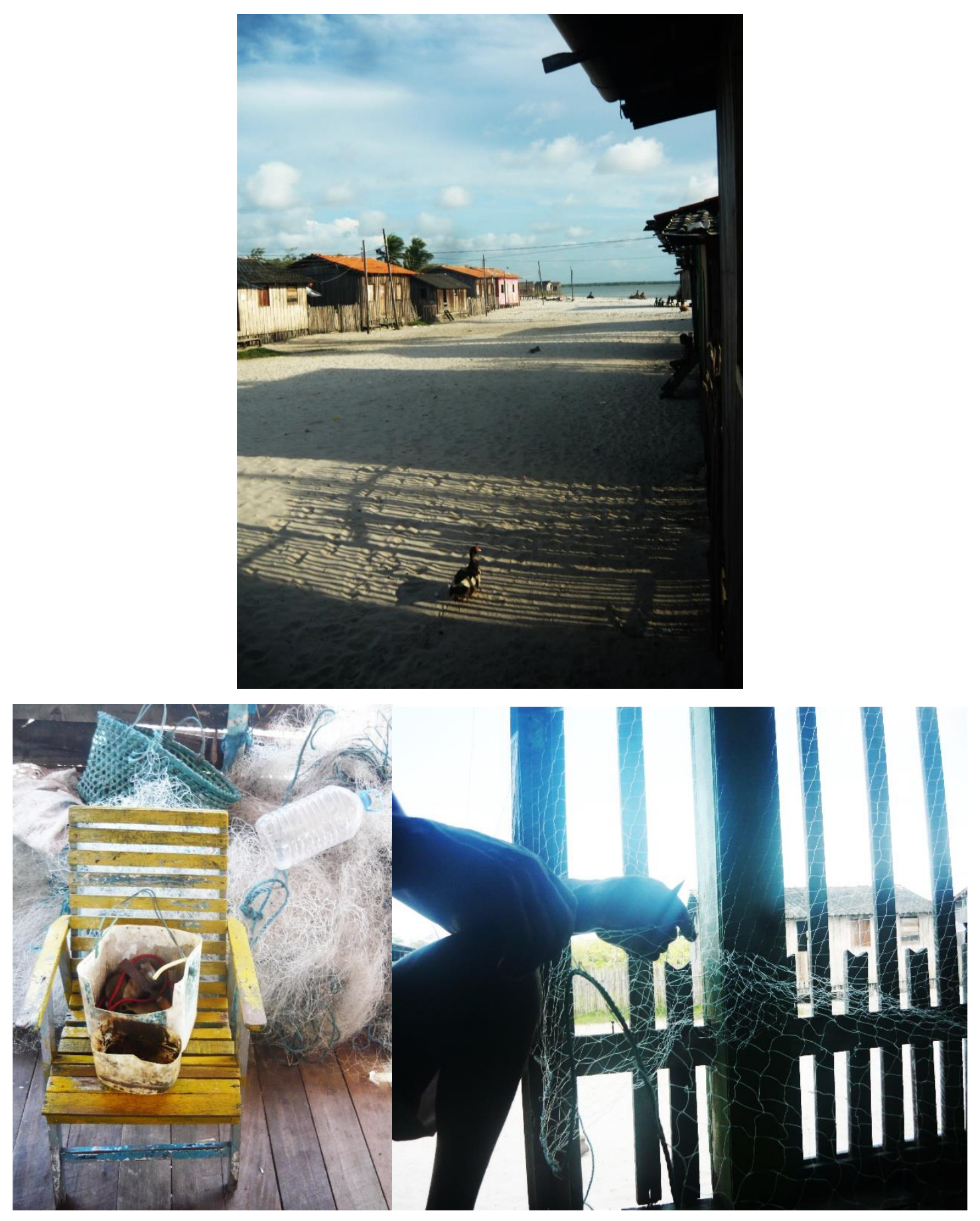



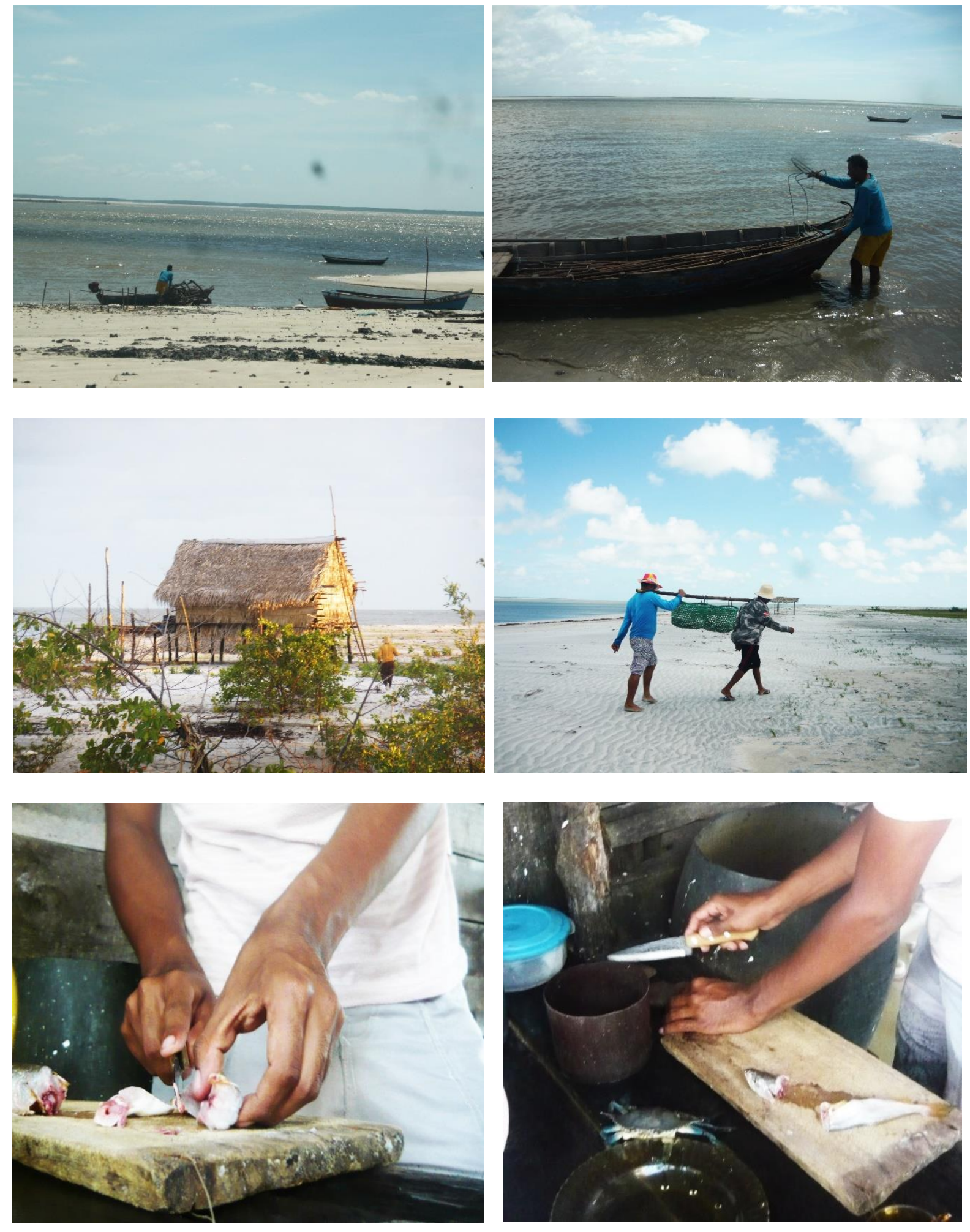


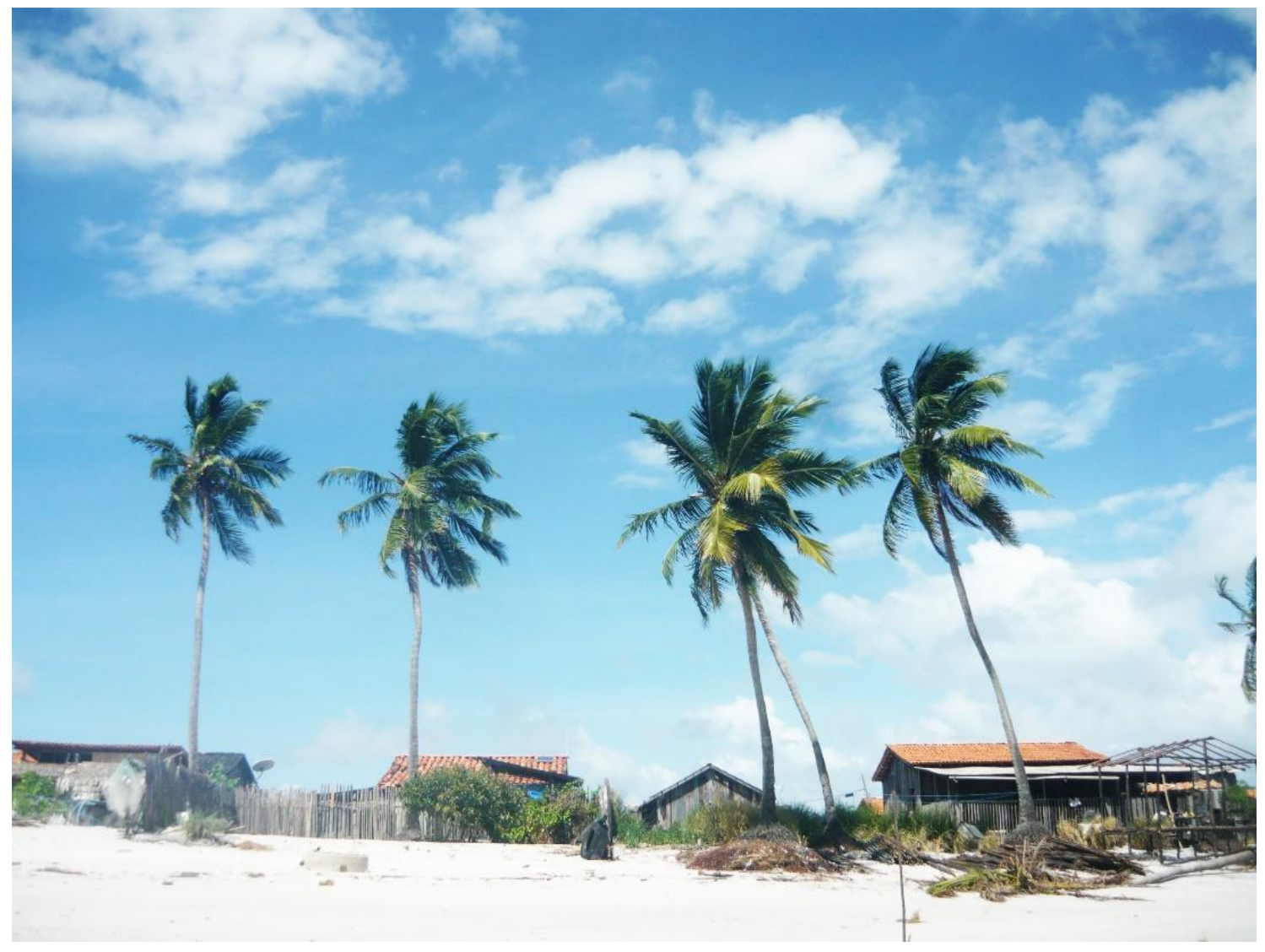

